\title{
LOW-BLANK CRUCIBLE FOR ARGON EXTRACTION FROM MINERALS AT TEMPERATURES UP TO $1550^{\circ} \mathrm{C}$
}

\author{
STANISLAW HALAS \\ Mass Spectrometry Laboratory, Institute of Physics, Maria Curie-Sklodowska University, \\ Plac Marii Curie-Skłodowskiej 1, 20-031 Lublin, Poland
}

\begin{abstract}
The new version of a double-vacuum crucible for fusion of small samples of refractory minerals has been described recently by Halas (2006). This novel type of high temperature crucible was further improved in the following important points: (1) The expensive material, tantalum, was replaced by much cheaper molybdenum which also appears to be significantly less corrosive in the presence of hot boron nitride ceramic used as the insulator, and (2) a versatile temperature controller was assembled from commercially available components.
\end{abstract}

Keywords: K/Ar dating, argon extraction, high temperature controller, vacuum

\section{INTRODUCTION}

A novel version of double-vacuum crucible for fusion of small samples of refractory minerals has been constructed recently in the Mass Spectrometry Laboratory at the Maria Curie-Skłodowska University. The new crucible successfully replaced a high-power Staudacher type furnace (Staudacher et al., 1978), commonly used in the $\mathrm{K} / \mathrm{Ar}$ and ${ }^{40} \mathrm{Ar}{ }^{39} \mathrm{Ar}$ dating methods (McDougall and Harrison, 1988). The new solution was first presented by the author during the $30^{\text {th }}$ International Conference on Vacuum Microbalance Techniques, which was held in Wroclaw (2005) and subsequently the full text was published in the Journal of Thermal Analysis and Calorimetry (see Halas, 2006). Since that time, not only a large number of $\mathrm{K} / \mathrm{Ar}$ dates were obtained, but also further improvements have been made.

This paper provides information on the following important improvements: (1) replacement of the expensive material, tantalum, by much cheaper molybdenum which also appears to be significantly less corrosive in the presence of hot boron nitride ceramic being used as the electric insulator, and (2) a versatile temperature controller was assembled from commercially available parts.

\section{CONSTRUCTIONAL DETAILS}

The crucible is made of a molybdenum cylinder, the top of which is welded to a titanium cylinder connected via a typical copper gasket to the inner vacuum system above the crucible. These welds are made by the electron beam in vacuum. The bottom part of the crucible is surrounded by a heater made of molybdenum wire insulated with boron nitride machineable ceramics, as shown in Figs 1 and 2. The heater assembly is immersed in high vacuum produced by an ion pump. The high-vacuum chamber is shown schematically in Fig. 3.

The temperature is measured by the Pt-PtRh thermocouple at the bottom of the crucible. This thermometer is also used for electronic control of the temperature. Another possibility is pyrometric temperature determination using a transparent window (a commercially available ultra-high-vacuum viewport) mounted at the top of the crucible. The window is protected against deposition of condensates of sample vapours by a home-made disc shutter. This shutter comprises a single nickel disc mounted in a thick $\mathrm{Cu}$ vacuum gasket. The nickel disc can be rotated manually by means of a small-size external magnet.

\section{TEMPERATURE CONTROLLER}

The schematic diagram of the temperature controller is shown in Fig. 4. We have installed in our circuit a so 


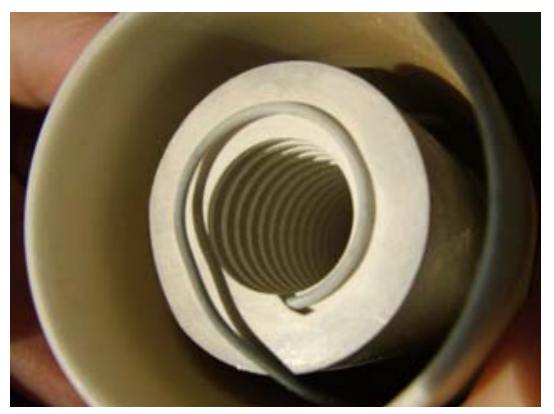

Fig. 1. The heater assembly made of molybdenum wire shaped into a helix, which is placed in the boron nitride ceramic insulator.

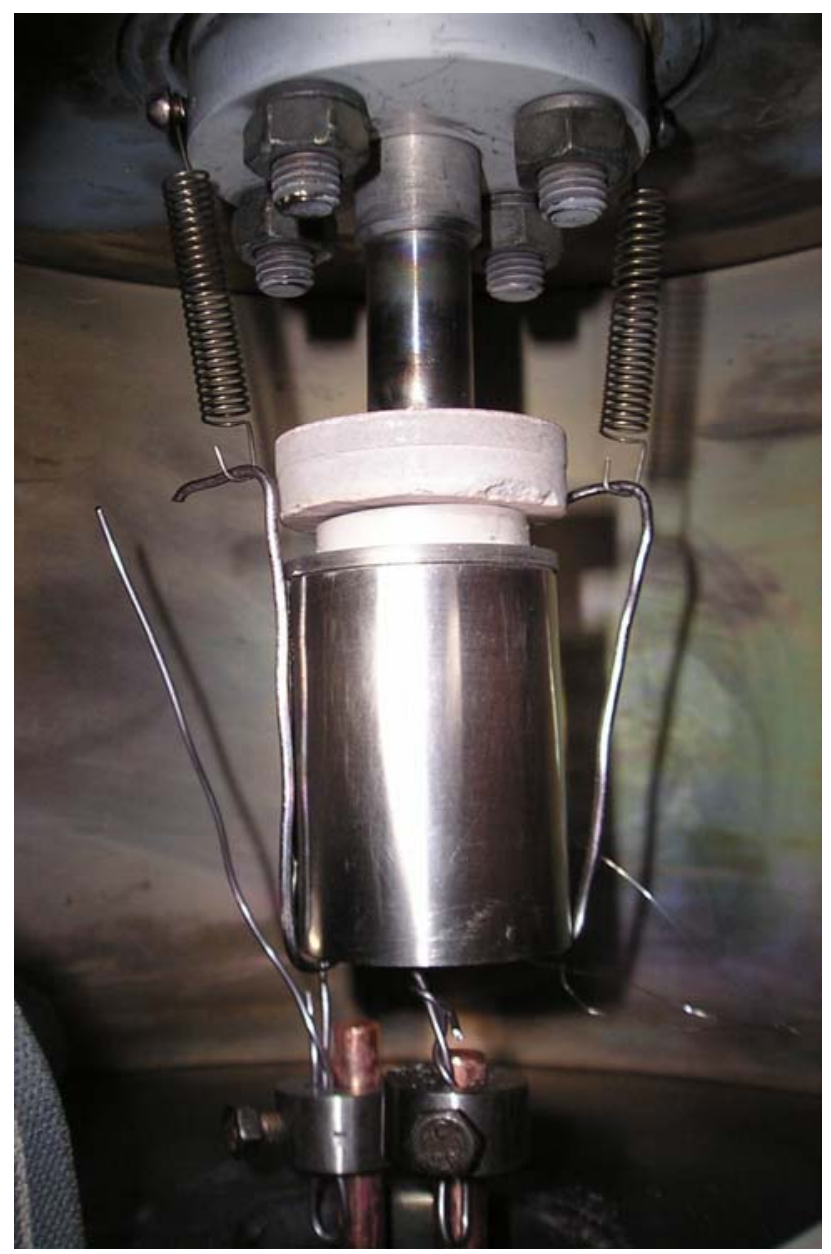

Fig. 2. The crucible with the heater.

called "fuzzy logic" ON/OFF controller, model BTC9090, supplied by LIMATHERM SENSOR (www.limatherm.pl). A desired temperature is set by the operator at the front panel of this microprocessor controller, where to its input the Pt-PtRh thermocouple is connected.

The crucible is heated by unfiltered DC current from the rectifier, shown at the top of the circuit diagram. The heating current flows only when the fife IRFZ44N transistors connected in parallel conduct, see the bottom right corner of the diagram in Fig. 4. The transistors conduct when their gates have a positive polarization supplied from a $5 \mathrm{~V}$ source through a phototransistor being controlled by a light emitting diode (LED) in the CNY 17 chip.

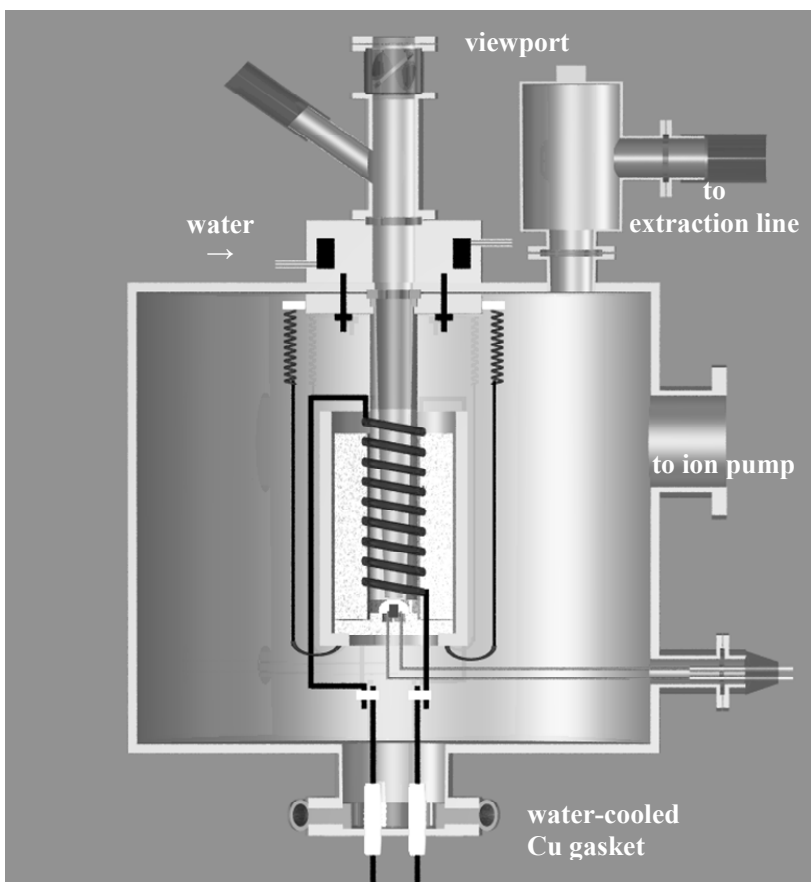

Fig. 3. A schematic cross-section through the crucible, heater and the vacuum chamber.

The remaining part of the whole circuit switches ON the controlling LED when the output switch in BCT 9090 is $\mathrm{ON}$, which can be made only when $\mathrm{AC}$ voltage in the output of the transformer is crossing null, what is detected by the circuit shown in the bottom left corner in the diagram in Fig. 4. Such a null detector protects the laboratory against electromagnetic noise which would be generated during an instant switching on a large current.

Note that the temperature controller is connected to net $230 \mathrm{~V}$ AC indirectly, but the power is supplied via $2.5 \mathrm{~kW}$ variac. The output voltage of the variac is adjusted by the operator in order to achieve the optimum ON/OFF switching action, i.e. when in a steady state condition the heating times and brakes are nearly equal.

\section{ACHIEVEMENTS}

The maximum temperature obtained in our crucible is $1550^{\circ} \mathrm{C}$, but higher temperature would be possible with the use of a more effective pump to produce the external vacuum. In our case, a small ion pump of $25 \mathrm{dm}^{3} / \mathrm{s}$ flow was applied. With this pump, the vacuum dropped to $10^{-3}$ Torr at $1550^{\circ} \mathrm{C}$, due to a strong degassing of the ceramics.

The temperature controller allows controlling the crucible temperature with an accuracy of several degrees of Celsius. When the voltage supply is raised gradually by means of a variac, then the controlling system has no tendency to exceed the selected temperature on the BTC-9090 module.

Our newly designed double vacuum crucible is used so far as a low-blank system for concentration determinations of noble gases in refractory minerals and glasses by means of static-vacuum mass spectrometry. In a routine sample analysis we noticed very high content of the radiogenic argon, frequently above $95 \%$ at $50 \mathrm{mg}$ samples 


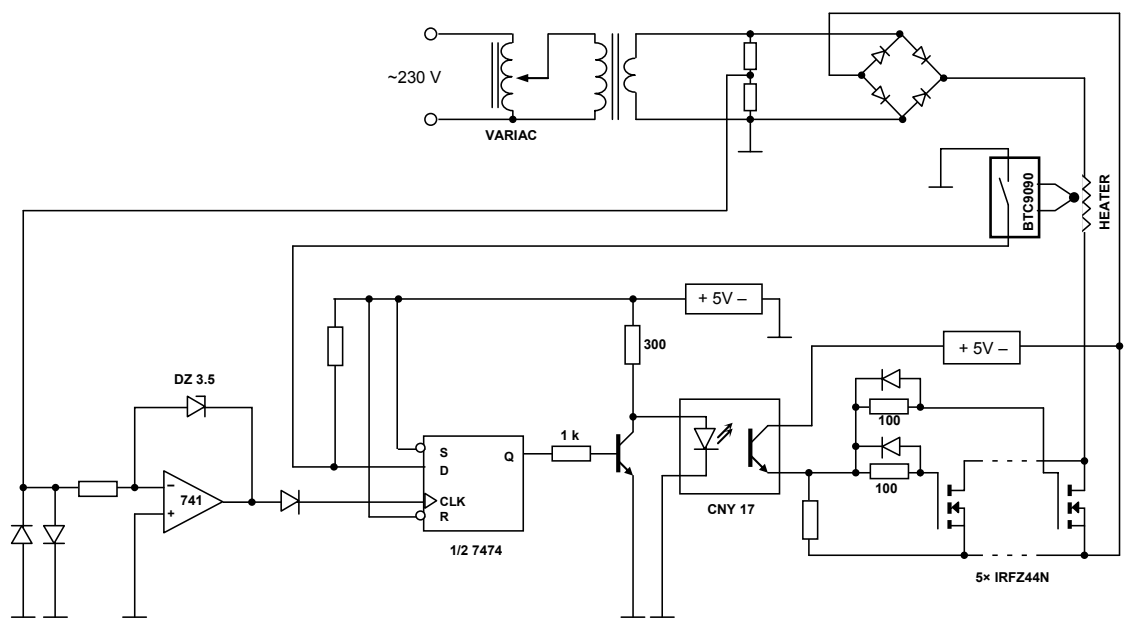

Fig. 4. Schematic diagram of the temperature controller. of Mesozoic biotite. This achievement enables us to analyze very small samples with a low radiogenic Ar content.

The present version of the low blank crucible differs from that already described by Halas (2006) by the replacement of the expensive tantalum by much cheaper molybdenum. The latter is long-lasting because it does not become fragile after contact with hot boron nitride. With this crucible all the argon gas may be extracted totally from refractory minerals like glasses, K-feldspar and hornblende in a single run or in a number of steps. The heating unit is characterized by a small heat capacity, thereby the final temperature is obtained quickly and safely, because the ceramic used is highly resistant to thermal shocks.

\section{ACKNOWLEDGEMENTS}

Thanks are due to my colleagues A. Wójtowicz and K. Pyszniak for their assistance in the design and assembling of the temperature controller circuit. Figs 3 and $\mathbf{4}$ were kindly drawn by Mr. Z. Dmitruk.

\section{REFERENCES}

Halas S, 2006. A double-vacuum crucible for temperatures up to $1600^{\circ} \mathrm{C}$. Journal of Thermal Analysis and Calorimetry 86: 31-33.

McDougall I and Harrison TM, 1988. Geochronology and Thermochronology by the ${ }^{40} \mathrm{Ar}{ }^{39} \mathrm{Ar}$ Method. Oxford University Press, New York: $212 \mathrm{pp}$.

Staudacher Th, Jessberger EK, Dorflinger D and Kiko J, 1978. A refined ultra-high vacuum furnace for rare gas analysis. Journal of Physics E: Scientific Instruments 11: 781-784. 